INTERNATIONAL BULLETIN

OF

BACTERIOLOGICAL NOMENCLATURE AND

TAXONOMY

Volume 5

Jaunary 15,1955

No. 1

\title{
A NEW SALMONELLA SEROTYPE (SALMONELLA COLINDALE) OF HUMAN ORIGIN
}

\author{
Audrey U. Price, M.B., B.S., D.P.H. \\ Salmonella Reference Laboratory, \\ Colindale, London, England \\ and \\ H.D. Holt, Dip. Bact., M.R.C.S., L.R.C.P. \\ Central Public Health Laboratory, \\ Colindale, London, England
}

\begin{abstract}
A woman of twenty-seven, employed as an air-stewardess, arrived in London on 16th December, 1951, after several days in Nigeria. Within twenty-four hours she developed acute diarrhoea, which lasted for more than a week. The infection might have been picked up in Nigeria, at any of several airports of call en route, or even in London. The patient's sister with whom she lives, and who gave a history of a similar attack two to three weeks previously, might have been excreting the organism. Unfortunately, the sister's faeces were not sent for examination.
\end{abstract}

\section{Bacteriology}

Faeces were cultured on the sixth day of the illness and an organism of the genus Salmonella was isolated.

This motile, Gram-negative bacillus produced a colony typical of a Salmonella on MacConkey agar. Glucose, maltose, mannitol, dulcitol, sorbitol, arabinose, rhamnose, xylose, trehalose, and inositol were fermented with the production of acid and gas. Lactose, sucrose, salicin, adonitol, inulin, and raffinose were not fermented after twenty-one days' incubation. The citrate (Simmons) utilization test was positive, hydrogen sulphide was produced, indole was not formed and urea was not hydrolyzed. The Voges-Proskauer test was negative, the methyl-red test positive, gelatin was not liquefied. Mucate was utilized and d-tartrate fermented. 
When examined serologically this organism was agglutinated to titre by $\underline{S}$. oranienburg $O$ serum, and slide-agglutinated by monospecific sera containing factors 6 and 7 . Reciprocal absorption tests showed that the somatic structure of the new serotype was identical with that of $\underline{\mathbf{S}}$. oranienburg.

The organism was diphasic. Phase 1 was agglutinated to titre by $\underline{\text { S. rubislaw }} H(r)$ serum, and reciprocal absorption tests proved that phase 1 was identical with $S$. rubislaw $H$ (r).

Phase 2 was agglutinated to titre by $\underline{S}$. gaminara $H(1,7)$ serum and, when tested with monospecific sera for factors $2,3,5,6$, and 7 , was agglutinated by factor 7 serum only. A suspension of the organism failed to remove all agglutinins from the $\underline{S}$. gaminara $H$ nonspecific serum. After absorption a titre of $1: 1600$ ( 16 per cent) was left to $\underline{S}$. gaminara $H$ nonspecific $(1,7+)$ and to $S$. isangi $H$ nonspecific $(1,5+)$ : suspensions of phase 2 of the new serotype, $S$. bredeney $H$ nonspecific, S. newport var. puerto rico, and $\mathrm{S}$. thomps on var. berlin were not agglutinated at a titre of $1: \overline{50} \overline{\text { Phase } 2}$ of the new serotype does not therefore contain the "plus" factor of $\underline{S}$. gaminara or $\underline{S}$. isangi, described by Hormaeche et al. $(1 \overline{4} 4)$.

$\bar{P}$ hase 2 was agglutinated to titre by $\underline{S}$. bredeney $H$ nonspecific serum and by absorption removed all homologous agglutinins from this serum. The serum made from the new serotype agglutinated $S$. bredeney $H$ nonspecific to titre and all homologous agglutinins were removed from it by a $\underline{S}$. bredeney suspension. Phase 2 of the new serotype is therefore, 1,7.

The antigenic structure is represented by the symbols $6,7: r: 1,7$.

The patient's serum taken on the seventeenth day after the onset of symptoms failed to agglutinate $\mathrm{O}$ and $\mathrm{H}$ suspensions of the organism at a dilution of $1: 20$.

Since this strain was received, five others have been identified, all from human faeces. Two cultures were isolated by Capt. J. Nagington, during the routine investigation of food-handlers; the patients were two healthy Cypriots in Fayid. Three cultures were is olated by Dr. E.H. Gillespie, two from patients in the same household, who were convalescent following an attack of Sonne dysentery, the third a healthy patient who was being investigated in relation to an sutbreak of staphylococcal food-poisoning. 


\section{Page 3}

BACTERIOLOGICAL NOMENCLATURE AND TAXONOMY

\section{SUMMARY}

A new Salmonella serotype $(6,7: \mathbf{r}: 1,7)$ is described, which was isolated from the faeces of a woman suffering from acute diarrhoea. The name of the new serotype is Salmonella colindale.

\section{REFERENCE}

Hormaeche, E., C.A. Peluffo, and V. Ricaud de Pereyra. A new salmonella type Salmonella carrau, with special reference to the $1,7 \ldots$ phases of the KauffmannWhite classification. J. Bact. 47:323-326. 1944 . 